eat or drink, It was not brown in colour. His bowels were opened on the first day, and there was a constipated result to an enema on the second day. Since then the constipation had been absolute. He had never had diarrhœea or been troubled with his bowels in any way. His right hip was ankylosed and he had been treated for tuberculous disease about five years previously. On admission : Temperature $97^{\circ} \mathrm{F}$. Pulse 80. Tongue slightly coated. The abdomen was distended and showed a definite ladder pattern with visible peristalsis. There was no ascites. The liver was not enlarged and no lump could be felt in the abdomen. On rectal examination scybala could be felt. An easily reducible left inguinal hernia was present. There were numerous scars over the right hip, one of which was discharging yellowish pus.

Operation. - An incision was made over the left rectus below the umbilicus, the muscle was split, and on opening the abdomen a small quantity of straw-coloured fluid was found. The small intestine was distended, but the cæcum was empty. The intestines were matted together by old fibrous adhesions. On tracing the distended intestine down a sharp kink was found, produced by a thick fibrous band attached to the mesentery and to the intestine midway between the mesenteric and the anti-mesenteric borders. This band was divided and the gut above emptied itself gradually past the stricture. The wound was closed in layers.

The patient died about 24 hours later with symptoms of ileus.

Post-mortem report.-Hæmorrhagic partial necrosis, in places almost perforated, of a knuckle of ileum $(6.5 \mathrm{~cm}$. long) situated $183 \mathrm{~cm}$. above the cæcum. This portion of gut lies free in the peritoneal cavity. Great distension and a few submucous hæmorrhages in small intestine above strangulation. Very slight fibrinous adhesions between coils of gut throughout abdomen, but no evidence of tuberculosis in these adhesions. Large indirect inguinal hernial sac left, reaching to bottom of scrotum and containing an easily reduced portion of pelvic colon. Collapse of large intestine. Great acid digestion of lungs with congestion. A few fibrous scars producing puckering of pleura apex of left lung. No fibrous pleural adhesions. No tuberculosis of mesenteric glands. Brown atrophy of the heart. Numerous puckered scars, some of them with shallow ulcers covered by scabs, around the right hip-joint. Considerable mobility in the joint.

\section{Remarks on Cases.}

The points of interest in these cases are: (a) The varying ages of the respective patients; $(b)$ the unusual nature of the causes of obstruction; (c) the impossibility of diagnosing the actual cause of obstruction before operation; $(d)$ the length of the history in the last three cases: $(e)$ the fact that in Case 3 apparently a previous strangulation had reduced itself three days before.

I am indebted to Sir Hugh Rigby and Mr. Robert Milne, under whom the cases were admitted, for permission to publish them.

\section{A CASE OF}

\section{CORNEO-SCLERAL CYST.}

BY H. Haward BYwater, M.D. WiCT., F.R.C.S. EdiN., HONORARY SURGEON, ST. PAUL'S EXE HOSPITAL, LIVERPOOI; AND

P. Eldoon Gorst, M.B., CH.B. Liverp., M.R.C.S., L.R.C.P. LOND.,

HONORARY ASSISTANT SURGFON, ST. PAUL'S EYE HOSPITAI, LIVERPOOL.

THE case is remarkable for the size of the cyst, which, being situated in the upper half of the right eye, extended across almost the whole length of the palpebral aperture, and caused very marked lagophthalmos.

J. C., a boy aged 9 year's, fell on the spout of a kettle three years ago. His right eve was cut. and he was taken to a hospital where the ere was stitched next day. He was in hospital for three weeks, and on leaving it could only see shadows. but no swelling was noticed for orer two years. When admitted to hospital he complained of no pain, but only of the discomfort and disfigurement that the swelling caused. He could still see shadows.

The cyst was roughly crescent-shaped and occupied the upper third of the cornea and the sclerotic above

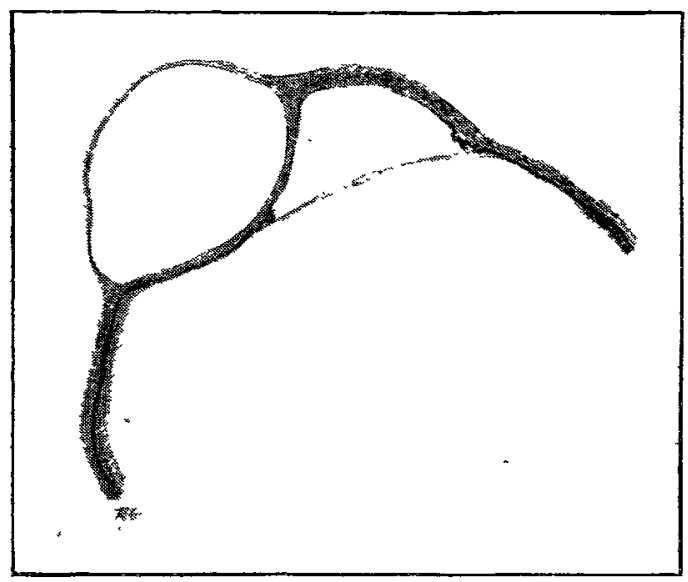

FrG. 1.- Showing general arrangement of cyst.

this and on either side. It measured $25 \mathrm{~mm}$, in the horizontal direction and $12 \mathrm{~mm}$. from before backwards at the point of its greatest depth. The upper lid barely covered the cyst. There was no ulceration present. There was no anterior chamber and no pupil was visible. The tension was +3 . No morements were seen in the cyst.

The eye was removed on August 14th, 1919. On section the cyst was found to contain clear fluid. It had the characteristics of an implantation corneo-scleral cyst. The iris was stretched in the vicinity of the cyst, but in

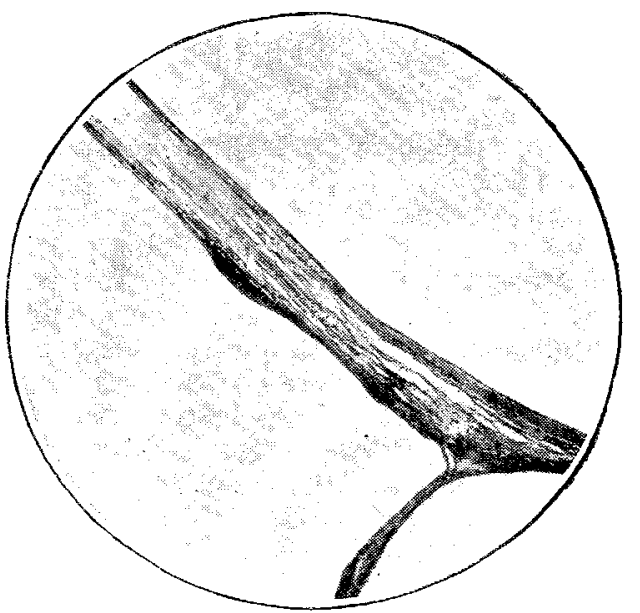

Frg, 2.-The corneal wall of the cyst, showing the corneal epitinelivm on one side and the epithelium lining the cyst on the other A projection of the epithelium into the carity of the cyst is shown

front was firmly adherent to the cornea. The posterior chamber was deepened, especially near the cyst, and pigmented bands of organised lymph could be seen in front of a small and fibrous lens. No communication could be made out between the cyst and the posterior. chamber. The optic nerre was cupped. The cyst was lined with squamous epithelium, which in places sent down projections which formed imperfect septa.

The sections here illustrated were made by Dr. Gorst at the Thompson Yates laboratories.

WeST CORNWALI INFIRMARY, PENZANCE-At the annual meeting of the aubscribers to this institution, which was recently beld, it was decided to make a public appeal for the erection of a children's ward. The cost of the scheme is estimated at $£ 12,000$, being $£ 5000$ for the building and $£ 7000$ for maintenance. It was reported that the late Mrs. D'Eata Oliver had bequeathed $\$ 3000$ to the funds of the charity. 